\title{
Dynamics between Disturbances and Motivations in Educational Mobile Games
}

\author{
https://doi.org/10.3991/ijim.v12i3.8490 \\ Nygren Eeva $\left({ }^{\square}\right)$ \\ University of Turku, Turku, Finland \\ eeva.nygren@kiteenkansanopisto.fi \\ Laine, Teemu $\mathrm{H}$. \\ Luleå University of Technology, Skellefteå, Sweden \\ Sutinen, Erkki A. \\ University of Turku, Turku, Finland
}

\begin{abstract}
Understanding engagement in games provides great opportunities for developing motivating educational games. However, even good games may induce disturbances on the learner. Therefore, we go further than presenting only results and discussion related to the motivation aspects and disturbance factors of the playing experience in UFractions (Ubiquitous fractions) storytelling mobile game. Namely, we define the dynamics between these two important game features. Sample of the case study was 305 middle school pupils in South Africa, Finland, and Mozambique.

Guidelines for game developers, users and educators were derived from the interplay of disturbance factors and motivations. Furthermore, we defined six different learning zones deriving from disturbances the player is facing and the player's motivation level.
\end{abstract}

Keywords-educational mobile game; serious game; motivation; disturbance factor; game design; fractions

\section{Introduction}

\subsection{Applying the styles to an existing paper}

Learning games have the potential for boosting intrinsic motivation [1], which may facilitate the learning process. However, little attention has focused on identifying the captivating features of games, especially serious games, and comprehensive model of motivations in educational games is lacking [2, 3].

Serious games and other digital learning systems often induce disturbances on the learner. Examples of disturbances are poor usability and poorly contextualized learning content [4]. We define disturbance factor (DF) as an element of a learning system that has a negative effect on the learner. In many cases, DFs can be remedied by ap- 
propriate technology integration referring to the process by which a technology (typically digital) is introduced to a learning context for facilitating effective pedagogical activities.

Thus, we will explore the role of motivations and DFs in educational mobile games and answer to the following questions:

1. What are the connections between game motivations and disturbance factors in the UFractions mobile game?

2. How can motivations and disturbance factors be taken into account in developing, setting up and using an educational mobile game?

3. What kind of learning do different combinations of motivations and disturbance factors promote?

As a case study, we present our experiences with the UFractions game that combines physical fraction rods with a virtual story-based game on a mobile device. The game was originally developed and evaluated in the South African context (2009), and was subsequently tested in Finland (2010) and in Mozambique (2011). In these three different contexts, we explored the roles of disturbance factors and motivations in search for answers to the research questions.

\section{Technology integration in context-aware mobile learning}

Mobile learning is a learning paradigm in which the learners with mobile devices have time and location independent access to learning resources. It has been extensively researched $[5,6,7]$ and it is often applied outside classrooms to complement formal educational systems.

We make a distinction between pure mobile learning and context-aware mobile learning. While both enable mobility of the learner, there is a difference in utilization of the surrounding context to enrich the learning experience. In pure mobile learning, content is only accessed through a mobile device and there is no connection to the context. This means that the learning content is essentially same in any context and no extra tools are required apart from the mobile device. In contrast, context-aware mobile learning purposefully takes advantage of resources available in the surrounding context. These resources can be for example observable phenomena such as weather, stationary objects such as a statue in a museum, or portable objects such as mathematical manipulatives.

We define disturbance factor $(D F)$ as an element of a learning system that has negative effect on the learner. By identifying and diminishing DFs we can improve technology integration of a context-aware mobile learning system. This idea was concretized in a technology integration evaluation tool [8] based on identified critical factors of technology integration (unobtrusive technology, available resources, context-awareness) and the concepts of active and passive integration. The tool also borrows the concepts of technology's affordances and constraints proposed by Koehler and Mishra [8] in their TPCK (Technological Pedagogical Content Knowledge) framework for classroom-based technology integration. Affordances are 
enabling features of an object or an environment that allow an individual to perform an action. Constraints are limiting forces that set restrictions on the use of technology.

We have previously analyzed the role of technology in the integration process in context-aware mobile learning [8] and divided technology integration into passive and active components.

- Passive integration: technology must be integrated into the learning system so that it becomes subtle and unobtrusive to the learner and to the context. In other words, technology is the object of integration.

- Active integration: technology must integrate the contextual resources and contextfree resources into the learning system and make the system adaptive to the changing situations of the context, including users within. In other words, technology is the subject of integration.

This division is essential in managing the technology's direct and indirect influences on the learner. Passive integration can be seen as the traditional type of integration that is applied to classroom technologies. The idea of active integration, enabled by technology integrated by passive integration, is novel as it adds context to the equation. Active integration strongly relates to context-aware mobile learning which depends on contextual resources. The goal of active integration is to establish a context-sensitive environment through adaptation of contextual resources and context-free resources to the learner's situation. Context-free resources are those that do not depend on the context, for example fraction theory. When the context of the learner changes, the technology automatically adjusts the resources to fit the new context.

\section{Motivation in Game-Based Learning}

Game-based learning offers a great potential to learning, especially in increasing motivation of learners. Evidently, there is a strong positive relationship between learning motivation and learning achievement $[9,10]$. However, the captivating features of commercial video games have not been successfully incorporated into educational games, and the potential of games is still widely unexploited in education $[2,3$, 11]. In order to create more fun, engaging and effective education, educators could learn from game designers how they keep the player engaged [12]. Existing theoretical frameworks developed in the literature on motivation and games may help us to understand engagement in games.

Motivation is the psychological feature that drives people to action [13]. The fundamental issue in psychology has been seeking answer to the question "Why do people do x?" [15]. A number of studies have been performed to identify people's motivations for playing computer games. Table 1 presents a comparison of six taxonomies of motivations. On one hand, these taxonomies clearly overlap, but on the other hand, they differ notably. Most of these motivational studies have concentrated generally on video games, multi-player games and online games, instead of serious games. At all events, it is clear that each taxonomy is pertinent in its own context. The reason for 
inequalities between the taxonomies is partly due to different contexts and types of the games, and partly due to different definitions of motivations. For example, teamwork, social interaction and socializing all sound similar, but they are defined slightly differently.

Bostan [15] examined a wide range of gaming motivations derived from the basic human needs. His study is based on the needs formalization of Murray [16], who diversified Maslow's work and identified 27 psychogenic needs that affect goaldirected human behavior. Murray emphasizes that a need is not a static entity; it comes into being, endures for a moment and perishes. Moreover, a need is a result of forces and may emerge together with other needs. Though each need is unique, there are similarities among them. Consequently, Murray divided 27 needs into primary needs related to physical satisfactions and secondary needs related to mental or emotional satisfactions, and more specifically into six classes, each class being a single major need [16]. Bostan [15] analysed these categories of needs, materialism, power, affiliation, achievement, information, and sensual needs, in relation to various gaming situations that can be experienced in computer role-playing games. Bostan points out that research has only been able to identify a limited set of motives related to digital games, and he suggests that analyzing motivations from the viewpoint of basic human needs leads to a broader range of gaming motivations, helping to understand the basics of goal-directed behavior in computer games.

The self-determination theory (SDT) also concentrates on people's innate psychological needs, but mainly on their inherent growth tendencies and on the different reasons or goals that give rise to an action. Deci and Ryan [10, p. 38] state that "selfdetermination is the capacity to choose and have those choices, rather than reinforcement contingencies, drives, or any other forces or pressures, be the determinants of one's actions". The consequential observation of self-determination theory is that motivation comes from two sources: extrinsic and intrinsic [10,17]. When a person is intrinsically motivated, he or she is doing something, because it is inherently interesting or enjoyable, and on the contrary, when a person is extrinsically motivated, he or she is doing something, because of the desire for some external reward, such as money or recognition from others. The quality of experience and performance varies to a great extent when one is behaving for intrinsic versus extrinsic reasons. Intrinsic motivation has become an important phenomenon for educators, because intrinsic motivation results in high-quality learning and creativity [17]. Using games for learning can enhance intrinsic motivation and add more to learning than just obtaining good grades [18].

Malone and Lepper [1] examined intrinsic motivation for learning in the field of computer games and produced a taxonomy of intrinsic motivations significant for gaming motivation research. Their taxonomy includes four individual motivations challenge, fantasy, curiosity and control - and three interpersonal motivations - cooperation, competition and recognition (Table 1). They formulated principles that can be used in designing intrinsically interesting learning environments, like constructing optimal level of challenge by clear, fixed goals and uncertain outcome. For example Ciamoa [19] perceived that Malone and Lepper'staxonomy of intrinsic motivations 
works well with grade 6 teacher's and students'when they are using mobile devices for learning.

The work of Malone and Lepper [1] inspired Garris, Ahlers, and Driskell [20] to present six dimensions or categories of instructional game characteristics: fantasy, rules/goals, sensory stimuli, challenge, mystery, and control. They also formulated an input-process-output model of instructional games and learning, and proposed that specific game features can trigger a repeating game cycle of user judgments, behavior, and feedback.

Table 1. A comparison of six studies related to motivations for play

\begin{tabular}{|c|c|c|c|c|c|c|c|}
\hline & $\begin{array}{c}\text { Malone } \\
\text { and Lep- } \\
\text { per (1987) } \\
\text { Computer } \\
\text { games for } \\
\text { learning }\end{array}$ & \begin{tabular}{|c|} 
Garris, \\
Ahlers, and \\
Driskell \\
{$[20]$} \\
Computer \\
games for \\
learning \\
\end{tabular} & $\begin{array}{c}\text { Sweetser } \\
\text { and Wyeth } \\
{[23]} \\
\text { Real-time } \\
\text { strategies } \\
\text { games }\end{array}$ & $\begin{array}{c}\text { Yee [21] } \\
\text { MMORPG } \\
\text { s }\end{array}$ & \begin{tabular}{|c|} 
Ryan, \\
Rigby \& \\
Przybyiski \\
{$[24]$} \\
Computer \\
games
\end{tabular} & $\begin{array}{c}\text { Fu, Su \& } \\
\text { Yu [25] } \\
\text { E-learning } \\
\text { games }\end{array}$ & $\begin{array}{l}\text { De Grove, } \\
\text { Cauberghe } \\
\text { \& Van } \\
\text { Looy [26] } \\
\text { Digital } \\
\text { Games }\end{array}$ \\
\hline Advancement & & & & $\mathrm{x}$ & & & \\
\hline Agency & & & & & & & $\mathrm{x}$ \\
\hline Autonomy & & & & & $\mathrm{x}$ & & \\
\hline Believability & & & & & & & $x$ \\
\hline Challenge & $\mathrm{x}$ & $x$ & $x$ & & & 6 elements & \\
\hline Clear goals & & & $\mathrm{x}$ & & & 4 elements & \\
\hline Competition & $x$ & & & $x$ & & & \\
\hline Competence & & & & & $\mathrm{x}$ & & \\
\hline Concentration & & & $x$ & & & 6 elements & \\
\hline Control & $x$ & $\mathrm{x}$ & $x$ & & & 7 elements & \\
\hline Cooperation & $x$ & & & & & & \\
\hline Curiosity & $\mathrm{x}$ & & & & & & \\
\hline Customization & & & & $\mathrm{x}$ & & & \\
\hline Discovery & & & & $x$ & & & \\
\hline Escapism & & & & $x$ & & & $x$ \\
\hline Fantasy & $\mathrm{x}$ & $\mathrm{x}$ & & & & & \\
\hline Feedback & & & $\mathrm{x}$ & & & 5 elements & \\
\hline Habit & & & & & & & $\mathrm{x}$ \\
\hline Immersion & & & $\mathrm{x}$ & 4 elements & & 7 elements & \\
\hline Involvement & & & & & & & $\mathrm{x}$ \\
\hline \begin{tabular}{|l|} 
Knowledge \\
improvement
\end{tabular} & & & & & & 7 elements & \\
\hline Mechanics & & & & $\mathrm{x}$ & & & \\
\hline $\begin{array}{l}\text { Moral } \\
\text { self-reaction }\end{array}$ & & & & & & & $\mathrm{x}$ \\
\hline Mystery & & $\mathrm{x}$ & & & & & \\
\hline Pastime & & & & & & & $\mathrm{x}$ \\
\hline
\end{tabular}




\begin{tabular}{|l|l|l|l|l|l|l|l|}
\hline Player skills & & & $\mathrm{x}$ & & & & \\
\hline Performance & & & & & & & $\mathrm{x}$ \\
\hline Recognition & $\mathrm{x}$ & & & & & & \\
\hline Relatedness & & & & & $\mathrm{x}$ & & \\
\hline Relationship & & & & $\mathrm{x}$ & & & \\
\hline Role-Playing & & & & $\mathrm{x}$ & & & \\
\hline Rules/goals & & $\mathrm{x}$ & & & & & \\
\hline $\begin{array}{l}\text { Sensory } \\
\text { stimuli }\end{array}$ & & $\mathrm{x}$ & & & & & \\
\hline $\begin{array}{l}\text { Social } \\
\text { interaction }\end{array}$ & & & $\mathrm{x}$ & & & 6 elements & \\
\hline Sociability & & & & & & & $\mathrm{x}$ \\
\hline Socializing & & & & $\mathrm{x}$ & & & \\
\hline Status & & & & & & & $\mathrm{x}$ \\
\hline Teamwork & & & & $\mathrm{x}$ & & & \\
\hline
\end{tabular}

Unlike most other taxonomies for gaming motivations, Yee's [21] motivation taxonomy is based on statistical methods. Yee's research identified 10 motivations that fall into 3 higher-level categories related to: achievement, social, and immersion motivations. In order to yield validation across different cultures of the scale as it stands, data from 2,071 American participants and 645 Asian participants from Hong Kong and Taiwan was used. [22]

Ryan, Rigby, and Przybyiski [24] applied SDT to investigate players' motives for computer game play. They proposed that need satisfaction predicts subsequent motivation to play, whereas need frustration predicts a lack of persistence. Four empirical studies examining properties of gaming environments and their associations with psychological need satisfactions provided evidence that games are initially motivating when players experience autonomy, competence and relatedness while playing (Table 1).

Eseryel et al [11] reinforced SDT with cognitive structure and problem representation theories. Their data-based research on massively multiplayer online games showed a result that one might not expect; interest and competence negatively predicted whether one chose to be engaged, the more disinterested and competent one was, the more they chose to take part. Additionally, there was also a positive influence on students' self-efficacy as seen by their engagement. It was further found that the students' perceived autonomy and experience relatedness had no influence on their engagement. When considering problem representation theories, it was found that students' engagement and their previous problem representation had a significant positive influence on their problem solving outcomes. Eseryel et al [11] also suggested that three kinds of interactions should be integrated with care into educational games in order to create ongoing motivation and engagement: interface, narrative and social interactivity. Interface interactivity has to do with players and game systems directly interacting. Narrative interactivity has to do with the players and the storyline directly interacting. Social interactivity has to do with human players directly collabo- 
rating and communicating. Additionally, they found that social interactivity during gameplay, including competition, is significant in contributing to learners' motivation, engagement, and development of complex problem-solving competencies.

The popular inducement used to explain enjoyment while playing games is the flow theory introduced by Csikszentmihalyi [27]. The concept of flow describes a person's preoccupation with the task at hand. Players often experience this heightened and improved state of mind while they are the most immersed in a game and performing at their best, thereby losing track of time and space. Sweetser and Wyeth (2005) created the GameFlow model for evaluating player enjoyment in games to build an understanding of enjoyment in games that is structured by flow. This model has been used to analyze especially real-time strategy games, and it consists of seven elements: concentration, challenge, player skills, control, clear goals, feedback, immersion and social interaction (Table 1). The GameFlow model was strengthened by Fu et al [25] and renamed as EGameFlow model containing 42 items divided into eight categories: (1) Concentration (6 items); (2) Goal Clarity (4 items); (3) Feedback (5 items); (4) Challenge (6 items); (5) Control (7 items); (6) Immersion (7 items); (7) Social Interaction (6 items); (8) Knowledge Improvement (7 items). De Grove et al [26] propose a systematic, theoretically and empirically grounded conceptual framework for digital game play reasons based on social cognitive theory. They suggest 10 outcomes for game play that can be seen as motivators from our viewpoint. (Table 1).

\section{$4 \quad$ UFractions}

The UFractions mobile game was developed in 2009 to help children at rural South African schools learn fractions and become motivated towards mathematics. It was later deployed in Finland (2010) and Mozambique (2011) in Finnish and Portuguese, respectively. The game combines a story-based game on a mobile device with physical fraction rods which are mathematical manipulatives that concretize learning abstract mathematical concepts (Figure 1). In the story, a leopard mother and her newborn cub adventure in savannah. The player solves fraction problems using the rods to help the mother leopard raise her cub. Raising the cub entails challenges such as finding food to eat, learning how to hunt, and finding sources of fresh water. When the player solves a fraction problem they are rewarded with points and the story continues. After a wrong answer the player may retry but the point value of the problem is decreased.

The fraction problems were designed so that the players must gain an understanding of the problem and the concept of fractions to be able to find the correct solutions. The problems require either a multiple choice or open field answers. An example problem is visualized in Figure 2. The fraction rods in UFractions represent different lengths which are mapped to respective colors. Thinking in terms of context-aware mobile learning, fraction rods in UFractions are contextual resources that connect with the game story and tasks. This connection is established by color codes on the rods and in the story (e.g. W for white, BL for blue). For each fraction problem, the 
game tells the player the colors and the codes of the fraction rods that are associated with that problem.

There is a context hint for each problem to provide scaffolding if the player fails to answer correctly. To decrease the risk of the game being too difficult (or easy), we organized game contents in three levels of increasing difficulty. To increase the player's control further, levels have also branches where the player can choose between easy and difficult story paths.

The leopards interact with the player through the mobile phone screen. Through this interaction, the player gains information on the leopards' lives and fraction theory. The aim of wrapping an appealing story around the pedagogical content was to make the players feel as if they would be playing and helping the leopards, not merely learning. The story is presented through the means of text, images and sound.

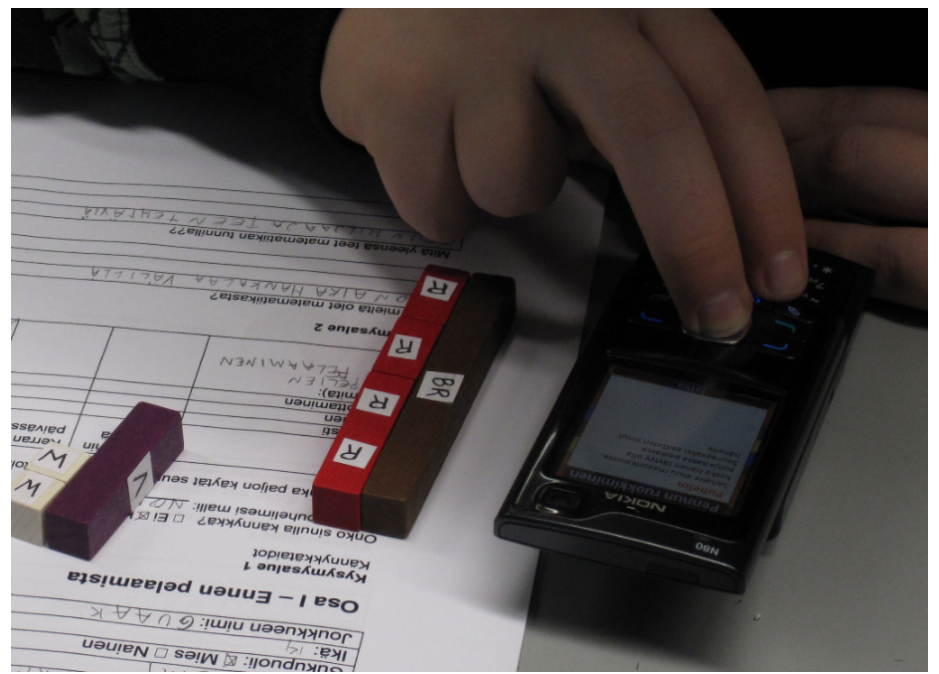

Fig. 1. UFractions combines a story on mobile phone and fraction rods

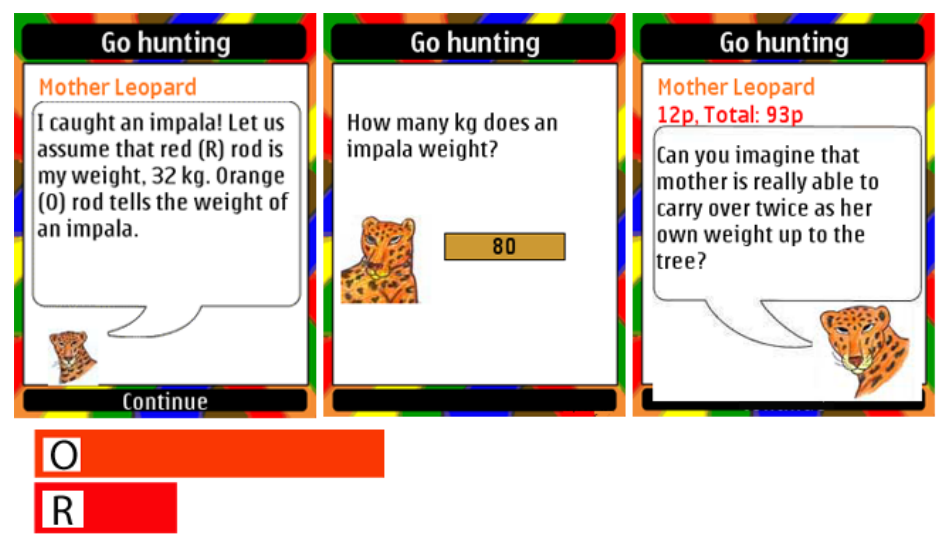

Fig. 2. Example of UFractions problem 
UFractions has also a feature that allows the players to identify and record evidence of fractions from everyday living environments by taking pictures and adding comments to the pictures. The evidence is submitted to the game website which also presents a real-time status of the leopards' and the players' struggle against hunger and enemies, scores of players, and guest book entries. A guest book entry can be authored after the player successfully finishes a level.

\section{Evaluation of UFractions}

\subsection{Evaluation Settings}

UFractions was tested using a mixed-method evaluation in three contexts: South Africa, Finland and Mozambique. Data collection instruments included questionnaires, interviews and observations. The evaluations in South Africa and in Finland were identical in terms of instruments, as the main purpose was to compare various aspects of the game play in two very different contexts. In Mozambique, we employed modified versions of the instruments that targeted at measuring technology integration. The following sections describe the research instruments used in the three contexts as well as the settings, target groups and procedures.

The evaluations were conducted in five schools in South Africa, four schools in Finland, and two schools in Mozambique during March 2009, March 2010 and MayJune 2011, respectively. In each country, we targeted at $8^{\text {th }}$ grade middle school pupils. Table 2 presents key figures related to the evaluation settings, including the number of participants, gender distribution, mobile phone ownership and median age. The total numbers of participants were 105 in South Africa, 104 in Finland and 96 in Mozambique. One distinctive feature of the Mozambican data set is that the participants were of 24 different nationalities whereas in South Africa and in Finland the participants were almost entirely locals. Furthermore, the participants at Polana Secondary in Mozambique were members of the Kids Club technology club where children apply and create novel information and communication technologies for learning.

In each context, the test procedure followed the following pattern. Before the evaluations, the researchers acquired necessary permission letters from the schools' and children's representatives. In the beginning, the researchers explained the purpose of the evaluation and shortly introduced the game's story and the usage of fraction rods. The participants then individually completed the first part of the questionnaire. After this, the teams of two to four students played the game for 30-45 minutes with fraction rods and mobile phones with the UFractions client software installed. During the game play, the researchers made observations and gave guidance to the participants when required. Upon finishing the game, the participants completed the second part of the questionnaire. Afterwards, the researchers interviewed three to five volunteer participants from each evaluation group. 
Table 2. Evaluation locations and participants

\begin{tabular}{|l|c|c|c|}
\hline \multicolumn{1}{|c|}{ South African Schools } & $\begin{array}{c}\text { Number of partici- } \\
\text { pants (males/females) }\end{array}$ & $\begin{array}{c}\text { Percentage of mobile } \\
\text { phone owners in test } \\
\text { group }\end{array}$ & Median age \\
\hline Alabama Secondary & $21(8 / 13)$ & $38 \%$ & 14 \\
\hline Lebone II & $22(11 / 11)$ & $77 \%$ & 13.5 \\
\hline Seiphemelo Secondary & $16(6 / 10)$ & $25 \%$ & 14 \\
\hline High School Zeerust & $27(11 / 16)$ & $78 \%$ & 14 \\
\hline Zinniaville Secondary & $19(8 / 11)$ & $84 \%$ & 13 \\
\hline \multicolumn{1}{|c|}{ Finnish Schools } & & & 14 \\
\hline Arppen Koulu & $32(14 / 18)$ & $100 \%$ & 14 \\
\hline Lieksan Keskuskoulu & $31(16 / 15)$ & $100 \%$ & 14 \\
\hline Joensuun Normaalikoulu & $18(9 / 9)$ & $100 \%$ & 14 \\
\hline Tietäväisen koulu & $23(14 / 9)$ & $100 \%$ & 15.5 \\
\hline \multicolumn{1}{|c|}{ Mozambican Schools } & & & 11 \\
\hline Kids Club at Polana Secondary & $16(11 / 5)$ & $50 \%$ & 13 \\
\hline Maputo International School & $54(32 / 22)$ & $80 \%$ & \\
\hline Matola Secondary School & $26(12 / 14)$ & $65 \%$ & \\
\hline
\end{tabular}

\subsection{Instruments in South Africa and Finland}

The questionnaire included open-ended and multiple choice questions with the Likert scale. The first part of the questionnaire collected demographics and background information such as mobile phone usage and feelings towards mathematics. The second part of the questionnaire measured the participants' perceptions on motivation, usability, game activities, game/learning experience, challenges and relevance to normal mathematics classes. The participant interviews aimed at gaining a deeper insight on participants' motivation as well as their perceptions on using the game as a learning tool and playing games in general.

\subsection{Instruments in Mozambique}

The primary aim of evaluating UFractions in the Mozambican context was to test technology integration. To achieve this aim, we developed a technology integration evaluation tool [8]. The tool follows a mixed-method approach and consists of questionnaires and interviews for both students and their teachers. These instruments measure aspects such as likes, dislikes, surprising elements, suggestions for improvement, usability, difficulties, motivation, and applicability of the system to other contexts. These aspects are used to evaluate the attractiveness of the system as a learning tool both from the learners' and the educators' perspectives. Furthermore, the qualitative data (open questions, interviews) aim at identifying DFs which have negative effect on the learners' experiences. 
The technology integration evaluation tool retains some of the components from the instruments used for evaluating UFractions in South Africa and in Finland. Specifically, demographics, background, usability and motivation meters are similar.

\subsection{Technology Integration Evaluation}

As we defined earlier, DF is an element of a learning system that has a negative effect on the learner. By identifying and diminishing DFs from a learning system we can improve technology integration (both active and passive).

To identify DFs in UFractions, we first analyzed qualitative data sets from South Africa and Finland and found 16 DFs [8]. We later used the technology integration evaluation tool in the Mozambican context. In this evaluation 22 DFs were identified including all but one of the previously discovered 16 factors. Table 3 presents the 22 DFs together with integration type (I: Active or Passive), and evidence samples from Mozambican data supporting the DFs. ZPD stands for Vygotsky's Zone of Proximal Development [28].

Table 3. Disturbance factors identified by the technology integration evaluation tool (adapted from [8])

\begin{tabular}{|c|c|c|}
\hline Disturbance factor & I & Evidence \\
\hline Too long game & A & "The game is very big. It must have been a bit shorter" (Male, 13, Indian) \\
\hline Too short game & A & $\begin{array}{l}\text { "I thought they could have a bit...maybe a bit longer the game." (Male, 12, } \\
\text { Mozambican) }\end{array}$ \\
\hline Beyond ZPD & A & $\begin{array}{l}\text { "There were some fractions that were difficult to solve." (Male, 13, Mozambi- } \\
\text { can) }\end{array}$ \\
\hline Below ZPD & A & $\begin{array}{l}\text { "For learning purpose maybe you should make it a little harder but as a game it } \\
\text { is ok.", (Male, 12, Indian) }\end{array}$ \\
\hline Wrong age group & A & $\begin{array}{l}\text { "Maybe it would be better for younger kids because it's this story of two leop- } \\
\text { ards, so it would be from } 8 \text { to } 11 \text {." (Female, } 13 \text {, Indian) }\end{array}$ \\
\hline Lack of scaffolding & A & $\begin{array}{l}\text { "Sometimes when you were doing a question and you keep on not understand- } \\
\text { ing I think there should be like where you can go to the next question if you } \\
\text { can." (Male, 11, Mozambican) }\end{array}$ \\
\hline Conflicting content & A & $\begin{array}{l}\text { "I was surprised because I had some answers that I was sure were correct but } \\
\text { somehow they were wrong" (Male, } 11 \text {, English) }\end{array}$ \\
\hline Too much story & A & "Too much reading and after a while it gets boring" (Female, 13, Mozambican) \\
\hline Monotony & A & $\begin{array}{l}\text { "A part that I didn't like was that it was always about leopards. If we had lots of } \\
\text { settings with maybe gorilla and rhino we could all learn the lives of lots of } \\
\text { animals which shows you lots of different fact. (Male, 11, Irish) }\end{array}$ \\
\hline Too educational & A & $\begin{array}{l}\text { "It was nice but the thing is like it's not something I wanna do on a weekend or } \\
\text { something. Maybe if you're bored..." (Male, 12, Indian) }\end{array}$ \\
\hline Harrassment & A & $\begin{array}{l}\text { "The thing was that two people would play it so one person would just take the } \\
\text { phone and the other person will take it. The other person would have taken it } \\
\text { and I couldn't have read so that was sort of a disadvantage. (Female, 11, Kore- } \\
\text { an) }\end{array}$ \\
\hline $\begin{array}{l}\text { Lack of peer sup- } \\
\text { port }\end{array}$ & A & $\begin{array}{l}\text { "Disadvantage is that maybe no one would be there to explain to you" (Female, } \\
13 \text {, Indian) }\end{array}$ \\
\hline Disturbing content & A & "The story of Senatla is not very good because the father of Senatla did not care \\
\hline
\end{tabular}


Paper-Dynamics between Disturbances and Motivations in Educational Mobile Games

\begin{tabular}{|c|c|c|}
\hline & & for Senatla. Senatla was living with her mother..." (Female, 17, Mozambican) \\
\hline Punishment & A & "[I disliked] When we got questions incorrect” (Male, 11, Mozambican) \\
\hline Lack of animation & $\mathrm{P}$ & $\begin{array}{l}\text { "I'd just say more animations into the story, kind of hide the fact that it's about } \\
\text { fractions. [...] (Male, 12, Indian) }\end{array}$ \\
\hline $\begin{array}{l}\text { Inappropriate } \\
\text { graphics }\end{array}$ & $\mathrm{P}$ & $\begin{array}{l}\text { "The screen was a bit too...all the colors around it and...it kind of...not too many } \\
\text { colors but all the colors around it were kind of distracting. It could be one plain } \\
\text { color maybe." (Male, 11, Irish") }\end{array}$ \\
\hline $\begin{array}{l}\text { Inappropriate } \\
\text { sounds }\end{array}$ & $\mathrm{P}$ & $\begin{array}{l}\text { "Make it more lively with sound" (Male, } 13 \text {, Mozambican) } \\
\text { "If you're gonna improve it, maybe you should like...let's say if someone has } \\
\text { troubles reading it you should have voice over" (Male, 12, Indian) }\end{array}$ \\
\hline $\begin{array}{l}\text { Inconvenient Inter- } \\
\text { action with rods }\end{array}$ & $\mathrm{P}$ & $\begin{array}{l}\text { "I wouldn't advise to use them because sometimes they make it complicated." } \\
\text { (Female, 15, Mozambican) }\end{array}$ \\
\hline $\begin{array}{l}\text { Inconvenient inter- } \\
\text { action with phone }\end{array}$ & $\mathrm{P}$ & $\begin{array}{l}\text { "One thing that I really didn't find that much interesting was using the phone. } \\
\text { That wasn't that much fun but I think that's all really.[...] There were buttons } \\
\text { and everything. I think it would be easier if you use something like maybe a } \\
\text { calculator or something." (Male, } 11 \text {, Mozambican) }\end{array}$ \\
\hline Technical faults & $\mathrm{P}$ & $\begin{array}{l}\text { "Once it turned down...it quit by itself but then we were on track again." } \\
\text { (Male, } 11 \text {, Irish) }\end{array}$ \\
\hline Small screen & $\mathrm{P}$ & $\begin{array}{l}\text { "The phone's screen was a bit too small so I couldn't see." (Female, 11, Kore- } \\
\text { an) }\end{array}$ \\
\hline $\begin{array}{l}\text { Unclear instruc- } \\
\text { tions }\end{array}$ & $\mathrm{p}$ & $\begin{array}{l}\text { "I didn't like some parts because I didn't quite understand some questions. Like } \\
\text { about four questions but the rest was ok." (Male, 12, Mozambican) }\end{array}$ \\
\hline
\end{tabular}

These DFs were brought up qualitatively by a subset of players. There were many players who very much liked the game and did not report anything negative about it. Thus, we cannot state that the discovered DFs render the game useless. However, it is important to pay attention to these aspects in future versions of the game to ensure the game's fluent operation. It is impossible to please everybody at all times but the system should be able to adapt the learning content through active technology integration to be suitable for a good majority of users. The tradeoff between available development resources and achieved benefits reminds us that a system, be it a game or any other application, can be sensibly improved only to a certain extent.

\subsection{Motivation Evaluation}

In this section, we present the results and discussion related to the motivation issues of the playing experience. A taxonomy for play motivations in the UFractions game was developed through a quantitative data analysis of the dataset collected through the questionnaires: altruism, challenge, curiosity, fantasy, relations and technology. The qualitative data analysis showed evidence of all six motivations and revealed an additional seventh play motivation for educational mobile games, namely cognitive restlessness [30].

The following are short descriptions of the discovered play motivations:

Altruism. Fantasies in computer games almost certainly awaken some emotional needs that the players want to satisfy [29]. The altruism motivation derives from the mission of the UFractions game - to help the leopards, because the story of the leopards and especially helping the cub appeal the altruism property in the players. Altru- 
ism is close to empathy and opposite to selfishness and egoism; it is the deliberate pursuit of interest or welfare in others or fictive characters and altruistic people help others unselfishly.

Challenge. Challenge can be defined by "difficulty in a job or undertaking that is stimulating to one engaged in it" . Evidently, challenge is one of the major causes for the flow experience. People prefer an optimal level of challenge; too easy or too difficult tasks do not maintain interest for a long time. A motivating game's structure should allow increasing or decreasing the level of challenges the player is facing, so that the skills of the player meet the level of the game missions [27]. According to Alessi and Trollip (2001), "challenge differs from a goal in that challenge is what one has to overcome or succeed to reach a goal".

Cognitive Restlessness. Cognition refers to the process of thought. Cognitive restlessness is about the desire to gain knowledge, to process information and to acquire knowledge using different methods. Games embody the process of cognitive disequilibrium, a concept defined by Piaget while he examined children and their learning [30]. People experience cognitive disequilibrium when there is a discrepancy between something new and what they already know or believe. This discrepancy produces a state of disequilibrium that drives people to eliminate it, in other words, to learn something new in order to achieve equilibration. According to van Eck (2006), the extent to which games accomplish cognitive disequilibrium without exceeding the capacity of the player to succeed largely determines the engagement in the game. The difference between cognitive restlessness and challenge is that challenge is more accompanied with reaching and accomplishing goals, and cognitive restlessness is about enjoying the way of learning.

Curiosity. The degree to which games can arouse and then satisfy players' curiosity is one of the most important features of intrinsically motivating games (Malone, 1981). According to Alessi and Trollip (2001), curiosity compels students to seek new knowledge and motivates them to learn beyond what they currently know or to explore further what is coming next in the game. Curiosity and challenge are closely related: they both often depend on the environment's adjustment to the learner's level of understanding and ability (Alessi \& Trollip, 2001; Malone, 1981). These two motivations are different for example in their relation to self-esteem - challenge engages the learner's sense of self-esteem, but curiosity need not engage self-esteem at all (Malone \& Lepper, 1987).

Fantasy. Fantasy is defined to be "a fantasy environment as one that evokes mental images of physical or social situations not actually present" (Malone \& Lepper, 1987). Many games involve fantasies to make them more interesting and more educational (Malone, 1981). The degree of fantasy can vary a lot from a close representation of reality to a more unrealistic imaginary story.

Relations. Relations is related to the social dimension, in other words to a preference for group work versus individual work. People who prefer individual values believe the individual is more important than the community or society, and people who prefer collective values believe the community or society is more important.

\footnotetext{
${ }^{1} \mathrm{http}: / /$ www.dictionary.com
} 
Technology. Technology refers to a variety of tools that might prove helpful in supporting the students' learning processes. The term technology deals with material objects and they can be modern technical devices, such as cellular phones, but also tangible manipulatives like fraction rods.

\section{The interplay of motivations and disturbance factors}

The connections between motivations and DFs are important to acknowledge because this knowledge may help us to diminish the DFs and thereby increase motivation while preventing undesired side effects. For example, if we would attempt to diminish the harrassment DF by disallowing the players to form groups then the relations motivation could become weaker. As another example, replacing physical fraction rods with virtual rods on a bigger screen might introduce new disturbances related to handling the rods through the user interface.

The relationships between identified motivations and DFs are described in Table 4. Each motivation relates to a set of DFs which typically have negative effects on the player's motivation. Exceptions are DFs marked with asterisks which may have positive effects on the respective motivations. For example, disturbing content can affect cognitive curiosity positively because it raises questions in the player's mind and therefore facilitates thinking process, thus potentially increasing the player's desire to learn more. The same applies to conflicting content which may cause the player to critically compare their own idea against the game's idea. Even though these positive disturbances were not sought after in the game design, they are significant outcomes. We divided technology into mental and physical based on how it is experienced by the player. We use the term physical for tactile user experience related to physical properties of the technology, whereas mental refers to non-physical properties of the technology experienced in non-tactile manner (e.g. visual, aural).

Table 4. Connections between motivations and disturbance factors in UFractions

\begin{tabular}{|l|l|}
\hline \multicolumn{1}{|c|}{ Motivation } & \multicolumn{1}{c|}{ Disturbance factors } \\
\hline Altruism & $\begin{array}{l}\text { Too long game, wrong age group, too much story, monotony, too education- } \\
\text { al, *disturbing content }\end{array}$ \\
\hline Challenge & $\begin{array}{l}\text { Too long game, below ZPD, beyond ZPD, wrong age group, lack of scaffold- } \\
\text { ing, *conflicting content, monotony, punishment, unclear instructions }\end{array}$ \\
\hline Cognitive restlessness & $\begin{array}{l}\text { Too long game, too short game, below ZPD, beyond ZPD, wrong age group, } \\
\text { lack of scaffolding, *conflicting content, too much story, monotony, too } \\
\text { educational, disturbing content, unclear instructions }\end{array}$ \\
\hline Curiosity - sensory & $\begin{array}{l}\text { Lack of animation, inappropriate graphics, inappropriate sounds, inconven- } \\
\text { ient interaction with rods }\end{array}$ \\
\hline Curiosity - cognitive & $\begin{array}{l}\text { Too long game, below ZPD, beyond ZPD, *conflicting content, too much } \\
\text { story, monotony, unclear instructions }\end{array}$ \\
\hline Fantasy & $\begin{array}{l}\text { Too long game, wrong age group, too much story, monotony, too education- } \\
\text { al, *disturbing content }\end{array}$ \\
\hline Relations & Harrassment, lack of peer support \\
\hline Technology - mental & Inappropriate graphics, inappropriate sounds, lack of animation \\
\hline Technology - physical & $\begin{array}{l}\text { Small screen, inconvenient interaction with phone, inconvenient interaction } \\
\text { with rods, technical faults }\end{array}$ \\
\hline
\end{tabular}


Figure 3 categorizes the identified motivations on the axes of active-passive technology integration and cognition-affection. As the figure illustrates, supporting motivations for both cognition and affection is important. Should we only emphasize the motivations connected to knowledge, the game would turn into a bad example of a serious game which would lack the emotional attachment that makes many games engaging. In another scenario, if we would reduce the value of knowledge and emphasize motivations connected to emotions, the game could become less educating and more drama-like. Finding a balance between cognition and affection depends on factors such as the game's type, context, topic and available technology.

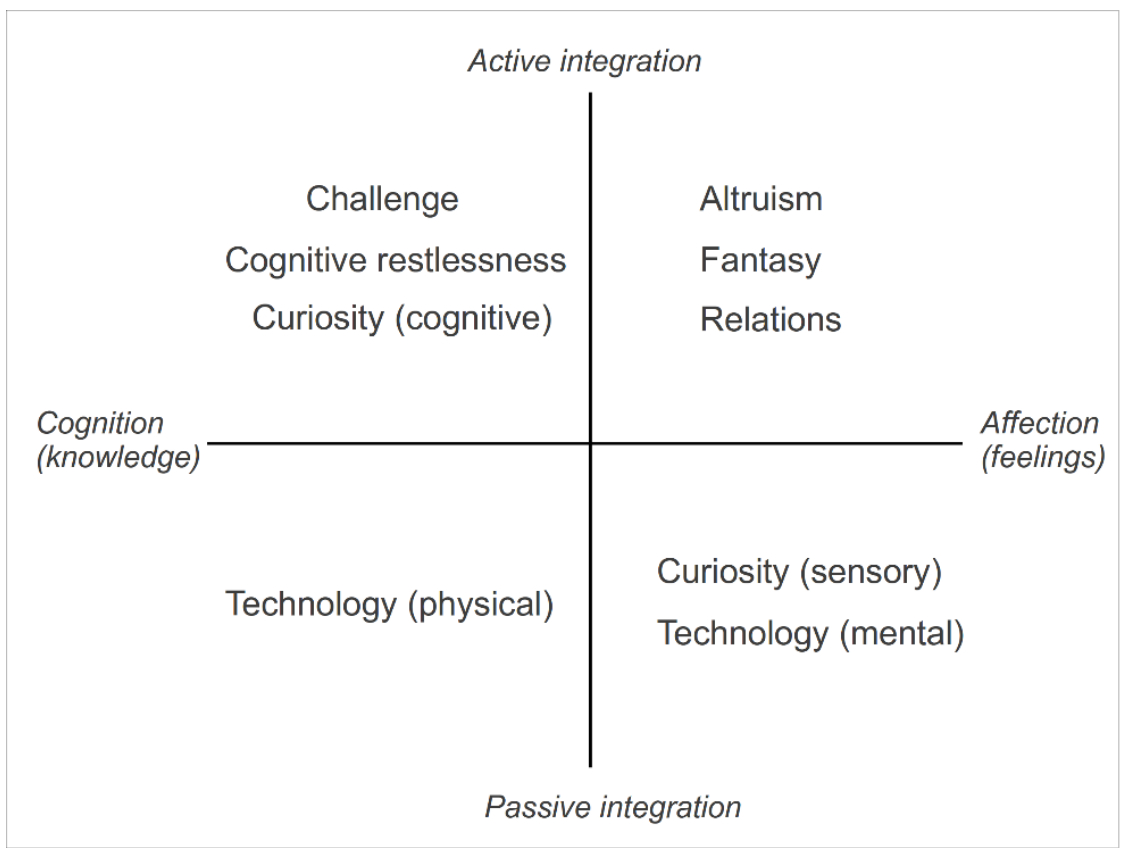

Fig. 3. Motivations in the dimensions of active-passive integration and cognition-affection.

Both motivations and DFs indicate that active integration is more critical in UFractions than passive integration. One reason for this is that technology used in UFractions is fairly simple and well known, while the game was tested by players originating from different contexts. The differences in players' contextual features, such as cultures, skill levels and personal preferences, are aspects where active technology integration should be further improved.

Together with sensory curiosity, technology is the only motivation that is affected solely by DFs connected to passive technology integration (that is, where technology is the object of integration). Mental experience of technology could be considered from the active integration point of view as well because graphics, sounds and other media can be seen as auxiliary vehicles for information contextualization. However, they are not actively performing the integration, thus we consider them from the perspective of passive integration. Finally, because most of the motivations relate to DFs 
of active integration, it is possible that the disturbances connected to the technology motivation (both physical and mental) are forgiven by the players if other motivations are strongly present in the game.

\section{$7 \quad$ Guidelines for pedagogical scenarios}

The categorizations presented in Table 4 and Figure 3 help us develop UFractions further to strengthen the motivations by diminishing identified DFs. From the interplay of DFs and motivations, we derived guidelines for game developers, users and educators as presented in Table 5.

Table 5. Guidelines for game developers, users and educators based on UFractions

\begin{tabular}{|c|c|c|}
\hline Target group & Guideline & Disturbance Factors \\
\hline \multirow{5}{*}{ Developers } & $\begin{array}{l}\text { Allow end users in different contexts to create stories to } \\
\text { promote ownership and improve contextualization }\end{array}$ & $\begin{array}{l}\text { Disturbing content, monotony, } \\
\text { wrong age group }\end{array}$ \\
\hline & $\begin{array}{l}\text { Include multiple modalities of media and presentation } \\
\text { templates that can be chosen by the user from game } \\
\text { preferences }\end{array}$ & $\begin{array}{l}\text { Monotony, Inappropriate } \\
\text { graphics, Inappropriate sounds }\end{array}$ \\
\hline & $\begin{array}{l}\text { Create multiple levels of challenge to accommodate } \\
\text { players with different abilities }\end{array}$ & Beyond ZPD, Below ZPD \\
\hline & $\begin{array}{l}\text { Enable gameplay with players' own devices to reduce } \\
\text { usability issues related to new technology }\end{array}$ & $\begin{array}{l}\text { Inconvenient interaction with } \\
\text { phone, small screen }\end{array}$ \\
\hline & Level test before playing & Beyond ZPD, Below ZPD \\
\hline \multirow{3}{*}{ Users } & $\begin{array}{l}\text { Work as a team: one member reads the story, others } \\
\text { handle rods. Roles can be changed after some time }\end{array}$ & $\begin{array}{l}\text { Lack of peer support, Harrass- } \\
\text { ment }\end{array}$ \\
\hline & $\begin{array}{l}\text { Read the instructions carefully to avoid losing points } \\
\text { because of misunderstanding }\end{array}$ & $\begin{array}{l}\text { Unclear instructions, Lack of } \\
\text { scaffolding }\end{array}$ \\
\hline & $\begin{array}{l}\text { Choose game level based on your skills. Choose level } 1 \\
\text { if you are unsure }\end{array}$ & Beyond ZPD, Below ZPD \\
\hline \multirow{5}{*}{ Educators } & $\begin{array}{l}\text { Ensure that the students possess necessary prerequisite } \\
\text { knowledge for learning the topics. }\end{array}$ & Beyond $\mathrm{ZPD}$, wrong age group \\
\hline & $\begin{array}{l}\text { Reconsider using another game or level if the students } \\
\text { already master the topics covered in the game or level. }\end{array}$ & Below ZPD, wrong age group \\
\hline & $\begin{array}{l}\text { Explain the use of auxiliary tools (e.g. fraction rods) to } \\
\text { students before playing the game for the first time. }\end{array}$ & $\begin{array}{l}\text { Inconvenient interaction with } \\
\text { rods, Unclear instructions }\end{array}$ \\
\hline & $\begin{array}{l}\text { Divide students into teams and assign roles to each } \\
\text { member (see above) }\end{array}$ & $\begin{array}{l}\text { Lack of peer support, Harrass- } \\
\text { ment }\end{array}$ \\
\hline & $\begin{array}{l}\text { Participate in technology training to learn how to solve } \\
\text { technical and usability problems }\end{array}$ & $\begin{array}{l}\text { Technical faults, Inconvenient } \\
\text { Interaction with rods and phone }\end{array}$ \\
\hline
\end{tabular}

Because development is a resource-intensive operation, we can maximize efforts by concentrating on the good sides of the game and make them stronger while eliminating critical disturbances that affect many motivations. It is important to keep in mind that diminishing one DF might strengthen others. For example, making the story shorter because a few players thought it is too long may cause more players to consid- 
er the game too short. Therefore, necessary precautions must be taken and constant evaluation applied to ensure that the changes do not produce undesired effects.

Our analysis of UFractions is not exhaustive, thus there may still be DFs and motivations to be identified. Furthermore, some of the DFs can be used to deduce latent motivations that could become active if the disturbances would be diminished. For example, harrassment of peers connects to the control motivation (or lack of it) identified by Malone and Lepper (1987). Note also that guidelines presented in Table 5 arise from the qualitative research findings on the UFractions game.

\section{$8 \quad$ Learning zones}

From the perspective of learning experience, an essential thing is how DFs and different motivations affect learning. By estimating intensity of DFs and motivational intensity, and placing them onto a $2 \times 3$ matrix, we can define six different learning zones while playing (Figure 4). The intensity of a DF means how much it irritates the learner or how seriously it affects the game play. Motivational intensity is the urge to engage in a behavior or the impulse to move toward or away from a stimulus [31]. In gaming, motivational intensity means how motivated the player is to continue playing and it can range on a dimension from low to high. We could say that when the DFs are too intensive, they become destruction factors. In fact, some DFs are so critical that the game becomes unplayable.

There are three zones of learning when motivational intensity is high:

1. FLOW ZONE: With low intensity of DFs, the game play happens in the flow state. Learning of the game content is effective.

2. CREATIVE ZONE: With medium intensity of DFs, students want to overcome the DFs and suggest actively improvements to the design and implementation of the game. In addition to learning well game content, students act as co-designers of the game and DFs bring reasonable challenges to extend their learning experience.

3. IRRITATION ZONE: With high intensity of DFs, students face so many DFs that game play is quite impossible. Students get irritated. Learning of the content might be weak. Although, because of the high motivation to play and learn, the learner may learn some other important things, for example to handle information and solve problems, and to apply self-made or ready-made computer programs as part of studying mathematics. These are mentioned as the learning objectives in the Finnish national core curriculum for basic education [32]. low:

Correspondingly, there are three zones of learning when motivational intensity is

4. ROUTINE ZONE: With low intensity of DFs, students get on playing. The game play happens routinely without disturbances. Learning of the game content is moderate.

5. APATHY ZONE: With medium intensity of DFs, students do not have sufficient motivation to independently overcome the DFs they are facing. They apathically 
wait for teacher's help, try some random solutions or quit playing. Learning is weak.

6. FRUSTRATION ZONE: With high intensity of DFs, students become frustrated. This state of mind affects negatively to learning; students do not want to overcome the DFs or learn the content.

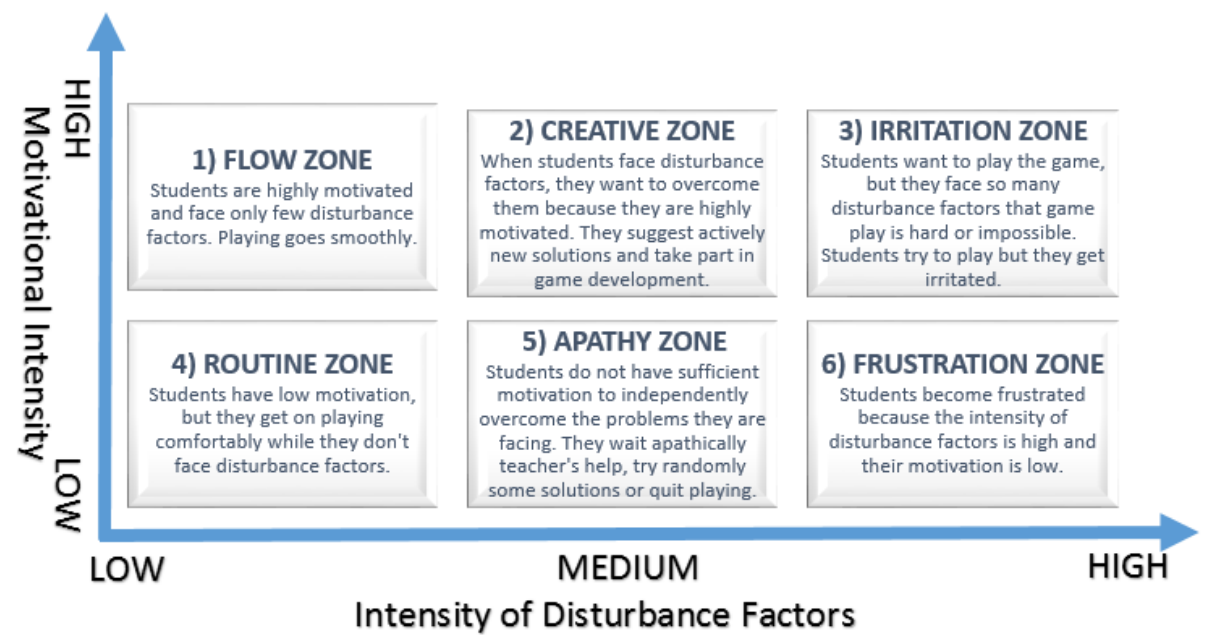

Fig. 4. Six different zones of learning according to motivational intensity and intensity of disturbance factors

From the learning zones, we notice that DFs with medium intensity may nourish the learning process in several ways:

- Affective learning: learning content is perhaps better remembered when the learning environment triggers strong emotions

- Critical thinking: DFs create disequilibrium, which can help the learner examine the subject of the lesson critically.

- Creative problem solving: if the problem cannot be resolved in an easy way due to DFs, then new, creative ways to solve the problem must be figured out. This, however, concerns wider problems than the UFractions exercises.

To get more extensive analysis, we could separate negative and positive DFs. Negative DFs are frustrating things that crucially affect the functioning of the game, like problems with network or the bugs that excessively interfere gaming. Positive DFs are kind of factors that do not have destructive effects on the game play. Negative DFs might cause more frustration than creativity. On the opposite hand, positive DFs are constructive DFs in the sense that they get students to the creative zone.

A similar idea has been applied in the field of leadership and management by Edmondson [33]. Competitive imperative of learning suggests shifting from "executionas-efficiency" to "execution-as-learning", meaning that instead of relentlessly and efficiently executing the consistent production and delivery of goods or services, the 
companies should create a psychologically safe environment where mistakes are approved and workers are encouraged collaboratively solve problems by using the best available knowledge. The workers are learning while they create effective processes. In game-based learning, from a point of view of learning, this means that ready-made polished learning games are not just "executed", but instead the game is allowed to be unpolished, i.e. include DFs. In addition to learning game content, the students are solving problems related to the game design, thus learning problem solving skills, design principles, and collaborative learning.

\section{Conclusions}

We analysed the dynamics between game motivations and DFs in the UFractions mobile game. Each motivation relates to a set of DFs which typically have negative effects on the player's motivation. By becoming aware of these relations, we are able to design more motivating educational games and give guidelines for game developers, users and educators. Different motivations and DFs can be taken into account in developing, setting up and using an educational mobile game.

We defined six learning zones by estimating intensity of DFs and motivational intensity, and placing them onto a $2 \times 3$ matrix. From these zones, we discovered that medium intensity of DFs nourishes the learning process. Thus, DF is not purely an element of a learning system that has a negative effect on the learner, but it can also be an element that challenges the learner to be more creative and broaden their perspective.

Our examination of different learning zones raises further questions like: Are the best learning games those that create lots of motivation and include only little DFs? Or those, that include also some DFs to get the players challenged to learn also other things than just the learning some precise content?

In order to build theoretically and empirically grounded conceptual framework for different learning zones related to educational digital games, a systematic motivation and DF examination of variety of games is needed, as well as study of dimensions of learning in different zones.

\section{References}

[1] T. W. Malone and M. R. Lepper, "Making learning fun: a taxonomy of intrinsic motivations for learning," Aptitude, learning, and instruction, 3, pp. 223-253, 1987.

[2] S. Egenfeldt-Nielsen, "Third Generation Educational Use of Computer Games," Educational Multimedia and Hypermedia, 16(3), pp. 263-281, 2007.

[3] R. van Eck, "Digital game-based learning: It's not just the digital natives who are restless," EDUCAUSEreview, march/april, 2006.

[4] A. Kukulska-Hulme, "Mobile Usability in Educational Contexts: What have we learnt?," The International Review Of Research In Open And Distance Learning, 8(2). Retrieved from http://www.irrodl.org/index.php/irrodl/article/view/356, 2007. https://doi.org/10.19 173/irrodl.v8i2.356 
[5] Eschenbrenner, B. and F. F. Nah, "Mobile technology in education: uses and benefits," International Journal of Mobile Learning and Organisation, 1(2), pp. 159-183, 2007.

[6] L. Naismith, P. Lonsdale, G. Vavoula and M. Sharples, "Literature review in mobile technologies and learning:," NESTA Futurelab Series, 2005.

[7] M. Sharples, M. Milrad, I. Arnedillo Sánchez and G. Vavoula, "Mobile Learning: Small devices, Big Issues, Technology Enhanced Learning: Principles and Products," pp. 233$249,2009$.

[8] T. Laine, E. Sutinen, M. Joy and E. Nygren, "Rapid improvement of technology integration in context-aware learning spaces," in Proceedings of the IEEE Africon 2011 Conference, (pp. 1-6), Livingstone, Zambia, 2011.

[9] M. J. Koehler and P. Mishra, Introducing Technological Pedagogical Content Knowledge, Routledge, 2008.

[10] C.-H. Su and C.-H. Cheng, "A mobile gamification learning system for improving the learning motivation and achievements," Journal of Computer Assisted Learning, pp. 13652729, 2015. https://doi.org/10.1111/jcal.12088

[11] E. Deci and R. M. Ryan, Intrinsic motivation and self-determination in human behavior, New York: Plenum Press, 1985. https://doi.org/10.1007/978-1-4899-2271-7

[12] D. Eseryel, V. Law, D. Ifenthaler, X. Ge and R. Miller, "An Investigation of the Interrelationships between Motivation, Engagement, and Complex Problem Solving in Game-based Learning," Educational Technology \& Society, 17 (1), p. 42-53., 2014.

[13] M. Prensky, "The Motivation of Gameplay," On The Horizon, vol. 10, no. 1, 2002. https://doi.org/10.1108/10748120210431349

[14] C. N. Cofer and M. H. Appley, Motivation: Theory and Research, New York: John Wiley \& Sons, 1967

[15] C. Nik, Introduction to work and organizational psychology: a European perspective, Cornwall: Blackwell Publishing, 2000.

[16] B. Bostan, "Player motivations: A psychological perspective," ACM Computers in Entertainment, 7(2), 2009.

[17] H. A. Murray, Explorations in personality, Oxford University Press, 1938.

[18] M. R. Ryan and E. L. Deci, "Intrinsic and Extrinsic Motivations: Classic Definitions and New Directions," Contemporary Educational Psychology, 25, pp. 54-67, 2000. https://doi.org/10.1006/ceps.1999.1020

[19] S. M. Alessi and S. R. Trollip, Multimedia for Learning: Methods and Development (3rd ed.), Boston: Allyn \& Bacon, 2001.

[20] K. Ciampa, "Learning in a mobile age: an investigation of student motivation," Journal of Computer Assisted Learning, pp. 1365-2729, 2014. https://doi.org/10.1111/jcal.12036

[21] R. Garris, R. Ahlers and J. E. Driskell, "Games, motivation, and learning: a research and practice model," Simulation \& Gaming, 33(4), pp. 441-467, 2002. https://doi.org/10.1177/ 1046878102238607

[22] P. Sweetser and P. Wyeth, "GameFlow: A model for evaluating player enjoyment in games," ACM Computers in Entertainment, 3(3), pp. 1-24, 2005. https://doi.org/10.1145/ 1077246.1077253

[23] N. Yee, "Motivations for play in online games," Cyberpsychology and Behavior, 9(6), pp. 772-775, 2006. https://doi.org/10.1089/cpb.2006.9.772

[24] M. R. Ryan, C. S. Rigby and A. Przybyiski, "The Motivational Pull of Video Games: A Self-Determination Theory Approach," Motivation Emotion, 30, pp. 347-363, 2006. https://doi.org/10.1007/s11031-006-9051-8 
[25] F.-L. Fu, R.-C. Su and S.-C. Yu, "EGameFlow: A scale to measure learners' enjoyment of e-learning games," Computers \& Education 52.1, pp. 101-112, 2009. https://doi.org/10.1016/j.compedu.2008.07.004

[26] F. De Grove, V. Cauberghe and J. Van Looy, "In Pursuit of Play: Toward a Social Cognitive Understanding of Determinants of Digital Play," Commun Theor, p. 24: 205-223, 2014.

[27] N. Yee, N. Ducheneaut and L. Nelson, "Online gaming motivations scale: development and validation," in Proceedings of the SIGCHI Conference on Human Factors in Computing Systems, 2012. https://doi.org/10.1145/2207676.2208681

[28] M. Csikszentmihalyi, Flow: the psychology of optimal experience, New York: Harper Collins, 1991.

[29] L. S. Vygotsky, Mind in Society: The Development of Higher Psychological Processes, Harvard University Press, 1978.

[30] E. Nygren, E. Sutinen, A. Blignaut and T. H. Laine, "Motivations for Play in the UFractions Mobile Game in Three Countries," IGI Global, pp. 30-48, 2012.

[31] T. W. Malone, "Toward a theory of intrinsically motivating instruction," Cognitive Science, 5(4), pp. 333-369, 1981. https://doi.org/10.1207/s15516709 $\operatorname{cog} 05042$

[32] J. Piaget, The child's conception of number., London: Routledge \& Kegan Paul ltd, 1969.

[33] E. Harmon - Jones, T. F. Price and P. A. Gable, "The influence of affective states on cognitive broadening/narrowing: Considering the importance of motivational intensity," Social and Personality Psychology Compass, 6(4), pp. 314-327, 2012. https://doi.org/10.1111/ j.1751-9004.2012.00432.x

[34] Finnish National Agency for Education, "Finnish core curriculum for basic education," Helsinki, 2014.

[35] A. C. Edmondson, "The Competitive Imperative of Learning," Harvard business review , pp. 1-10, 2008.

\section{Authors}

Eeva Nygren is a PhD candidate at the University of Turku. Nygren received MSc Degree in Mathematics in 2003 and post-graduate degree (Licentiate of Philosophy) in 2005 from the University of Joensuu. Since then she has worked as a mathematics teacher and vice principle in the Evangelical Folk High School of Kitee. Her main research interests are integrating educational technology into teaching, educational games and tutoring systems.

Dr. Teemu H. Laine received a $\mathrm{PhD}$ in Computer Science from the University of Eastern Finland in 2012. He worked more than five years as Assistant Professor at the Ajou University in the Republic of Korea before assuming his current position as Associate Professor at the Luleå University of Technology in Sweden. His current research focuses on context-aware games for education and well-being, and his other research interests include augmented and virtual reality, software architectures, and ICT for development.

Dr. Erkki Sutinen is a full professor of Computer Science at the University of Turku. He has a wide expertise in the uses of information and communication technologies for development (ICT4D), computer science and ICT education, creative problem solving, and contextual design. Prof. Sutinen has a 6 M Euros portfolio of 
R\&D projects, funded by various sources. The latest are "Improving the contextual impact of ICT education in southern Tanzania: Engaging stakeholders towards innovation", and "Towards e-leadership: higher profitability through innovative management and leadership systems". Prof. Sutinen has, in addition to several university positions in many countries, worked as the chief technical advisor of STIFIMO, a 22 Million Euro science, technology and innovation program between Finland and Mozambique. He has supervised or co-supervised 25 Ph.D.s and served as a reviewer as several international journals and conferences, Ph.D. committees, and research proposals.

Article submitted 22 February 2018. Resubmitted 17 and 24 April 2018. Final acceptance 08 May 2018. Final version published as submitted by the authors. 